Fetal Diagnosis

and Therapy
Fetal Diagn Ther 2017;41:293-299

DOI: $10.1159 / 000448947$
Received: February 22, 2016

Accepted after revision: August 5, 2016

Published online: September 3, 2016

\title{
Automated Measurement of the Angle of Progression in Labor: A Feasibility and Reliability Study
}

\author{
Aly Youssef ${ }^{a}$ Ginevra Salsi $^{\mathrm{a}}$ Elisa Montaguti ${ }^{\mathrm{a}}$ Federica Bellussi ${ }^{\mathrm{a}}$ \\ Giuseppina Pacella $^{\mathrm{b}}$ Carlotta Azzarone ${ }^{\mathrm{a}}$ Antonio Farina ${ }^{\mathrm{a}}$ Nicola Rizzo $^{\mathrm{a}}$ \\ Gianluigi Pilu ${ }^{\mathrm{a}}$ \\ a Department of Obstetrics and Gynecology, Sant'Orsola-Malpighi University Hospital, University of Bologna, \\ Bologna, and ${ }^{b}$ Department of Medicine and Surgery, Università Campus Bio-Medico di Roma, Rome, Italy
}

\section{Key Words}

Labor - Ultrasound - Three-dimensional sonography ·

Delivery · Intrapartum ultrasound - Angle of progression .

Transperineal ultrasound · Automated measurement

\begin{abstract}
Objectives: The aim of this paper was to assess the feasibility and reliability of a new automated method for the measurement of the angle of progression (AoP) in labor. Methods: AoP was assessed using two-dimensional transperineal ultrasound by two operators in 52 women in active labor to evaluate intra- and interobserver reproducibility. The intermethod agreement between automated and manual techniques was analyzed by means of the intraclass correlation coefficient and Bland-Altman method. Results: Automated measurements were feasible in all cases. Automated assessments correctly depicted the pubic symphysis and fetal head in 133 (85.3\%) out of 156 on first assessments and in all 156 after repeating measurements once in case of incorrect first evaluation. The automated technique showed good intraand interobserver reproducibility and very good agreement with the manual technique. AoP measured by the automated method were significantly wider than those done by the manual technique $\left(119 \pm 20^{\circ}\right.$ vs. $\left.130 \pm 20^{\circ}, p=0.005\right)$. Con-
\end{abstract}

\section{KARGER}

(C) 2016 S. Karger AG, Basel

E-Mail karger@karger.com

www.karger.com/fdt clusions: Automated assessment AoP is feasible and reproducible. However, measurements performed by the automated software are significantly different from those resulting from the previously published manual technique. In the light of our data, the automated technique does not seem ready yet for clinical use, and the AoP should be exclusively measured by the previously suggested manual technique.

(c) 2016 S. Karger AG, Basel

\section{Introduction}

The use of transperineal ultrasound for the assessment of fetal head descent and progression has been suggested as an adjunct to clinical examination [1-10]. Whereas clinical examination is subjective with uncertain reproducibility [11], intrapartum transperineal ultrasound (ITU) has the advantages of being objective and highly reproducible $[1,4,10,12-16]$.

The angle of progression (AoP; or angle of descent 'AoD') is the angle between the longitudinal axis of the pubic bone and a line joining the lowest edge of the pubis to the lowest convexity of the fetal skull (fig. 1) [4]. AoP is an accurate and reproducible means for assessing descent of the fetal head during labor $[6,13,17]$. AoP has

Dr. Aly Youssef

Department of Obstetrics and Gynecology, Sant'Orsola-Malpighi University Hospital, University of Bologna

Via Massarenti 13, IT-40138 Bologna (Italy)

E-Mail aly.youssef78@gmail.com 
also been found to strongly correlate with the sonographically determined head station, allowing for conversions between the two parameters [8]. Furthermore, many studies have demonstrated a strong association between AoP and labor outcome $[4,6,7,18-20]$.

The introduction of ITU in routine clinical practice has proven to be challenging [21]. This is thought to be partly due to the complexity of the technique and the currently suggested ITU parameters $[21,22]$. In a recent survey, we have found that up to two thirds of obstetricians considered the ITU parameters used for fetal head descent too complex for clinical application [21]. The latter obstacle may be overcome by the availability of reliable and accurate software, which automatically calculates the desired ITU parameters. In fact, the use of automated measurements has been demonstrated to reduce the time needed for some biometric evaluation, and it has been advocated that automated techniques may improve the work flow efficiency [23]. This may be particularly useful in the labor ward where efficiency, simplicity and speed are of utmost importance.

In the present study, we provide data on a novel automated technique for the assessment of the AoP in labor by two-dimensional ultrasound. The aim of this study was to evaluate the feasibility and reliability of this method. In addition, we aimed to evaluate the intermethod agreement between automated and traditional manual techniques.

\section{Materials and Methods}

From March to April 2015, a nonconsecutive series of women in active labor (defined as cervical dilatation of more than $3 \mathrm{~cm}$ and regular contractions) with a singleton, uncomplicated term (37-42 weeks) pregnancy and fetuses in vertex presentation were recruited for the aim of the study. Patient enrollment was carried out when one of the investigators was available in the labor ward. The obstetrician performing the ultrasound examination was present in the labor ward exclusively for this aim and was not aware of the clinical examination of the women, except for the cervical dilatation.

The fetal head station in relation to the ischial spines was assessed by digital examination, as suggested by the American College of Obstetricians and Gynecologists [24], in the absence of uterine contractions or maternal pushing. The clinical examination was performed by the midwife responsible for the laboring women, and she was blinded to the result of the ultrasound examination. Immediately following the clinical examination, an ITU examination was performed.

Ultrasound Examination

A transperineal, two-dimensional ultrasound scan was performed in the mid-sagittal plane using a portable machine (Volu- son P8; GE Medical Systems, Zipf, Austria) equipped with a convex probe covered by a sterile glove. The ultrasound machine used was equipped with a novel software (Sono Labor \& Delivery; GE Medical Systems) with a dedicated option designed to automatically detect the echogenic center of the maternal symphysis pubis, the fetal head, and to measure the AoP in an automated manner (fig. 1,2). AoP is the angle between a line running along the long axis of the pubic symphysis and another line extending from the most inferior portion of the pubic symphysis tangentially to the fetal skull contour [4]. Operator 1 (A.Y.) measured AoP by using the 3-point-angle option on the ultrasound machine. The technique using the 3-point angle to measure the AoP will be described as the manual technique in this paper. Operator 1 then used the automated technique to measure AoP twice in order to assess intraobserver variability. Subsequently, Operator 2 (F.B.), blinded to all previous measurements, assessed AoP once by the automated technique. All ultrasound assessments were performed with women in the modified lithotomy position in the absence of maternal pushing and uterine contractions referred by the women or detected on the tocography regularly offered to all women in our labor ward. Each assessment was performed on a separate ultrasound image obtained for each measurement.

Prior to the beginning of patient recruitment, both operators performed more than 50 automated acquisitions each in order to become familiar with the new software (training phase). During the initial training phase, both operators noted that in a few cases, the software erroneously detected other structures not related to the symphysis pubis and the fetal skull instead. This resulted in meaningless measurements (fig. 3). It was therefore decided to visually assess each automated measurement, to discard those associated with inappropriate structure identification and to immediately perform a second measurement on a newly acquired ultrasound image in these cases.

\section{Statistics}

The means, medians, SD, ranges and frequencies were used as descriptive statistics. Agreement between the two operators and between the two measurements made by Operator 1 as well as the intermethod agreement between the automated and manual techniques, were expressed using intraclass correlation coefficients (ICCs) for single measurements and 95\% CI for the ICC [25]. ICC values under 0.20 were considered poor, $0.21-0.40$ fair, $0.41-0.60$ moderate, $0.61-0.80$ good and $0.81-1.00$ very good or excellent. The systematic differences were also computed using the paired Student $t$ test. As far as repeatability is concerned, in order to assess systematic bias between the intraobserver, interobserver and intermethod measurements, the differences between the values were plotted against the means of the measurements, as described by Bland and Altman [26], and the limits of agreement were evaluated together with their 95\% CI [26]. The repeatability coefficients were also computed [27]. The first measurement of Operator 1 was used to assess the intraobserver and intermethod agreement. The statistical analyses were performed using SPSS version 13.0 (SPSS Inc., Chicago, Ill., USA), and two-tailed p values $<0.05$ were considered statistically significant.

\section{Statement of Ethics}

The study protocol was approved by the local ethical committee, and a consent form signed at the onset of labor was obtained from each eligible patient. The study protocol conforms to the eth- 
Fig. 1. Technique for the measurement of the AoP. The convex transducer, covered by a sterile glove, is positioned translabially on the median plane (a), demonstrating the pubic symphysis (PS) and the fetal skull (b). The AoP is measured as the angle between two lines: the first one running along the long axis of the pubic symphysis (c), and the second one extending from the most inferior portion of the pubic symphysis tangentially to the fetal skull contour (d).
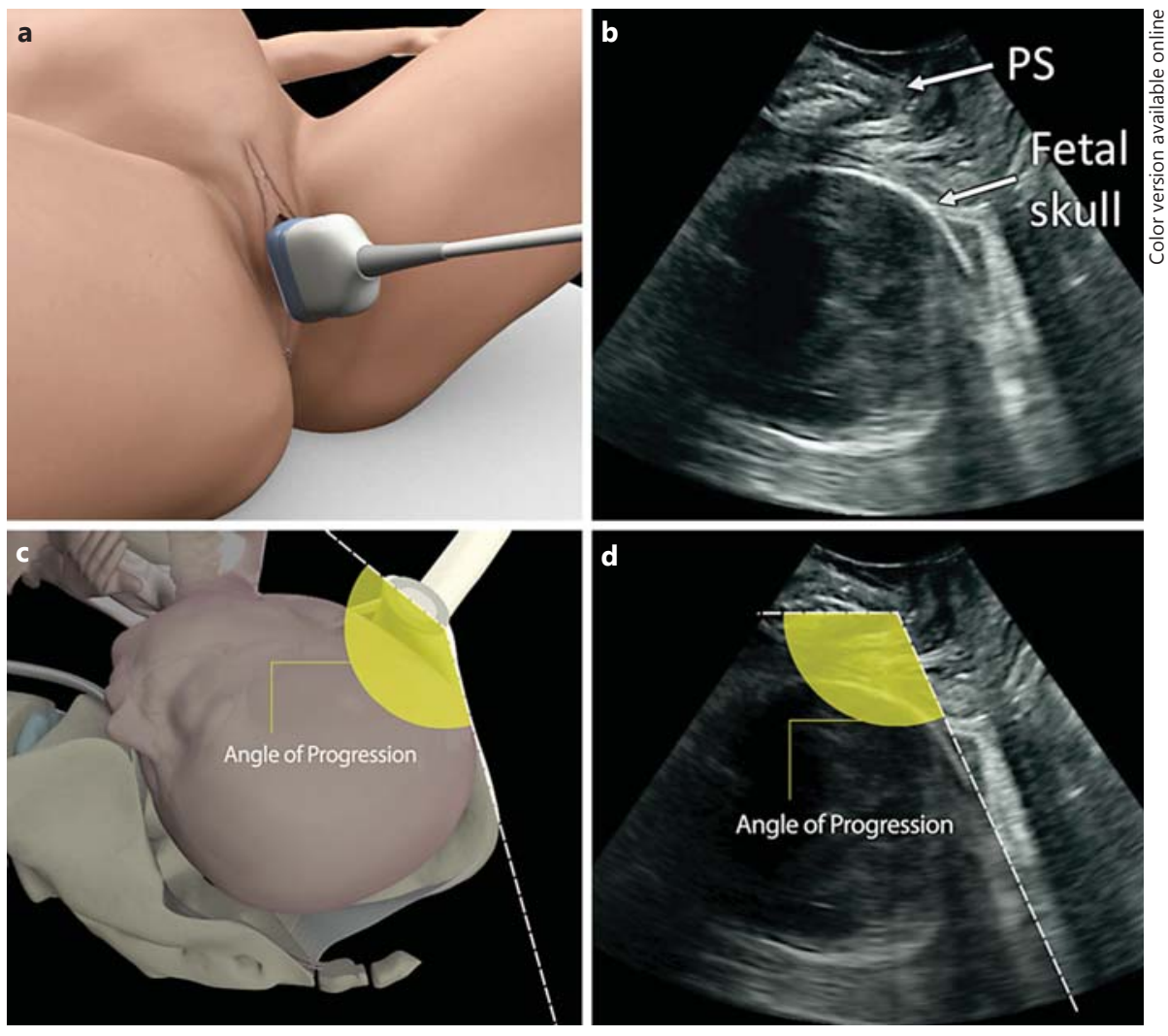

Fig. 2. The measurement of the AoP using the manual (a) and the automated (b) techniques.

Fig. 3. The uncommon event of wrong depiction of the pubic symphysis (a) and the fetal head (b). In a, the software automatically detected retropubic soft tissue as the pubic symphysis, whereas in $\mathbf{b}$, the software seemingly detected the echogenic rectal content as the fetal head.
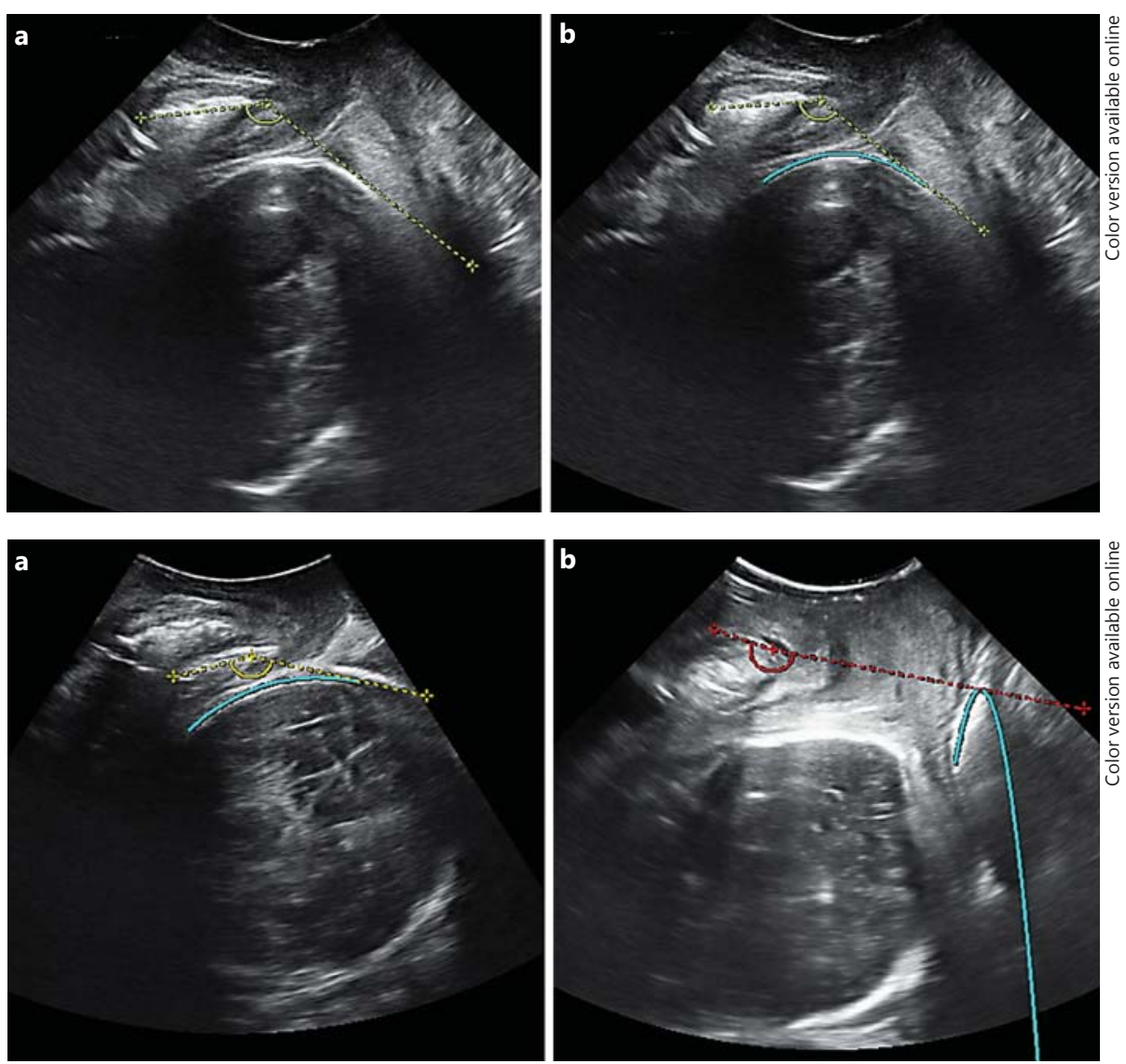

Automated Measurement of Angle of Progression

Fetal Diagn Ther 2017;41:293-299 
Table 1. Characteristics of the 52 women included in the study

\begin{tabular}{|c|c|}
\hline $\begin{array}{l}\text { Maternal age, years } \\
\text { Gestational age, weeks } \\
\text { BMI }\end{array}$ & $\begin{array}{l}33(18 \text { to } 45) \\
39(37 \text { to } 41) \\
25.6(20.90 \text { to } 33.9)\end{array}$ \\
\hline $\begin{array}{l}\text { Stage at scan } \\
\text { First stage } \\
\text { Second stage }\end{array}$ & $\begin{array}{l}26(50) \\
26(50)\end{array}$ \\
\hline $\begin{array}{l}\text { Cervical dilatation at scan, } \mathrm{cm} \\
\text { Fetal head station } \\
\text { Induction of labor } \\
\text { Epidural analgesia }\end{array}$ & $\begin{array}{l}8(4 \text { to } 10) \\
0(-4 \text { to } 4) \\
18(34.6) \\
30(57.7)\end{array}$ \\
\hline $\begin{array}{l}\text { Parity } \\
0 \\
1 \\
2\end{array}$ & $\begin{aligned} 42 & (80.8) \\
8 & (15.4) \\
2 & (3.8)\end{aligned}$ \\
\hline $\begin{array}{l}\text { Mode of delivery } \\
\text { Spontaneous vaginal delivery } \\
\text { Instrumental vaginal delivery } \\
\quad \text { (vacuum) } \\
\text { Cesarean section }\end{array}$ & $\begin{array}{l}39(75.0) \\
9(17.3) \\
4(7.7)\end{array}$ \\
\hline $\begin{array}{l}\text { AoP } \\
\text { Operator } 1 \text { (automated, first } \\
\quad \text { measurement) } \\
\text { Operator } 1 \text { (automated, second } \\
\quad \text { measurement) } \\
\text { Operator } 2 \text { (automated) } \\
\text { Operator } 1 \text { (manual) }\end{array}$ & $\begin{array}{l}130^{\circ}(103 \text { to } 206) \\
127^{\circ}(94 \text { to } 210) \\
130^{\circ}(102 \text { to } 234) \\
119^{\circ}(86 \text { to } 218)\end{array}$ \\
\hline
\end{tabular}

ical guidelines of the "World Medical Association Declaration of Helsinki - Ethical Principles for Medical Research Involving $\mathrm{Hu}$ man Subjects' adopted by the 18th WMA General Assembly, Helsinki, Finland, in June 1964 and amended by the 59th WMA General Assembly, Seoul, South Korea, in October 2008.

\section{Results}

The characteristics of the 52 women included in the analysis are shown in table 1. Overall, 52 manual and 156 automated measurements of AoP were performed. Automated measurements were judged acceptable in 133 (85.3\%) out of 156 on the first assessments and in all 156 after repeating measurements once for unacceptable evaluations. Measurements were repeated due to incorrect pubic symphysis and fetal head automated detection in 13 $(8.3 \%)$ and $10(6.4 \%)$ cases, respectively. The incidence of occiput posterior position at digital examination was not different in women with unacceptable first measurements in comparison with those who had acceptable first images ( $7 / 23$ vs. $35 / 133, p=0.422)$. In addition, there was no difference in station between the 2 groups $(\mathrm{p}=0.609)$. The results of the analysis of the intraobserver, interobserver and automated versus the manual intermethod agreement of AoP are presented in table 2, and the results of the Bland-Altman plots are displayed in figures $4 \mathrm{a}-\mathrm{c}$. The automated technique showed good intra- and interobserver reproducibility. The automated technique demonstrated a very good agreement with the traditional manual technique, but AoP measured automatically were significantly wider than those calculated manually (119 \pm $20^{\circ}$ vs. $\left.130 \pm 20^{\circ}, \mathrm{p}=0.005\right)$. The difference between automated and manual measurements was not affected by the fetal head station (Pearson $\mathrm{r}=-0.110, \mathrm{p}=0.437$ ).

Following the finding of a systematic overestimation of the AoP by the automated software, the first author has re-evaluated all images of automated measurements to identify possible causes of that systematic error. Two main potential causes were detected. The first one lied in the design of the software. The automated software was designed to depict the symphysis pubis by drawing a line through its echogenic center. Whereas the underestimation of the pubic symphysis' length was by only few millimeters, it is likely that this contributed to the observed systematic overestimation of AoP. A demonstration of that effect is illustrated in figure 5. Another possible cause of angle overestimation by the automated technique was the identification of caput succedaneum instead of the fetal skull. This was observed in a very few cases and was apparently significant only in 1 case (fig. 6).

\section{Discussion}

In the present study, we provided original data on the use of new software measuring the most studied ITU parameter: AoP. The automated technique was able to calculate AoP in all cases and could correctly detect the main two structures needed to measure this parameter from the first time in the vast majority of cases. Visual confirmation was required, however, as in $15 \%$ of the cases automatic identification of the structures failed. The automated measurements of AoP were reproducible and showed a very good agreement with the traditional manual measurements. However, angles calculated by the automated software were significantly wider in comparison with the manual technique.

The use of ITU enables the objective measurement of birth progress and improves the understanding of normal and abnormal labor $[8,20,28,29]$. In particular, AoP 
Table 2. Summary of intra- and interobserver reliability for automated measurements as well as automated versus manual intermethod reliability for the assessment of the AoP in labor in the studied population $(n=52)$

\begin{tabular}{|c|c|c|c|}
\hline Parameter & Intraobserver & Interobserver & $\begin{array}{l}\text { Intermethod } \\
\text { (automated vs. manual) }\end{array}$ \\
\hline Mean difference $(95 \% \mathrm{CI}){ }^{\circ}$ & $-1.039(-6.074$ to 3.997$)$ & $-3.019(-8.107$ to 2.069$)$ & $11.308(7.554$ to 15.061$)$ \\
\hline Range of differences, ${ }^{\circ}$ & -62 to 44 & -68 to 58 & -16 to 67 \\
\hline Systematic difference $\mathrm{p}$ value $\mathrm{a}^{\mathrm{a}}$ & 0.799 & 0.468 & 0.005 \\
\hline ICC (95\% CI) & $0.752(0.568 \text { to } 0.858)^{*}$ & $0.779(0.616 \text { to } 0.873)^{*}$ & $0.865(0.766 \text { to } 0.923)^{*}$ \\
\hline \multicolumn{4}{|l|}{$95 \%$ LOA $\left(95 \%\right.$ CI), ${ }^{\circ}$} \\
\hline Upper & $35.27(26.44$ to 44.10$)$ & $33.67(24.75$ to 42.60$)$ & $38.38(31.79$ to 44.96$)$ \\
\hline Lower & $-37.35(-46.18$ to -28.52$)$ & $-39.71(-48.64$ to -30.79$)$ & $-15.76(-22.34$ to -0.918$)$ \\
\hline Repeatability coefficient, $^{\circ}$ & 36.31 & 36.69 & 27.07 \\
\hline
\end{tabular}
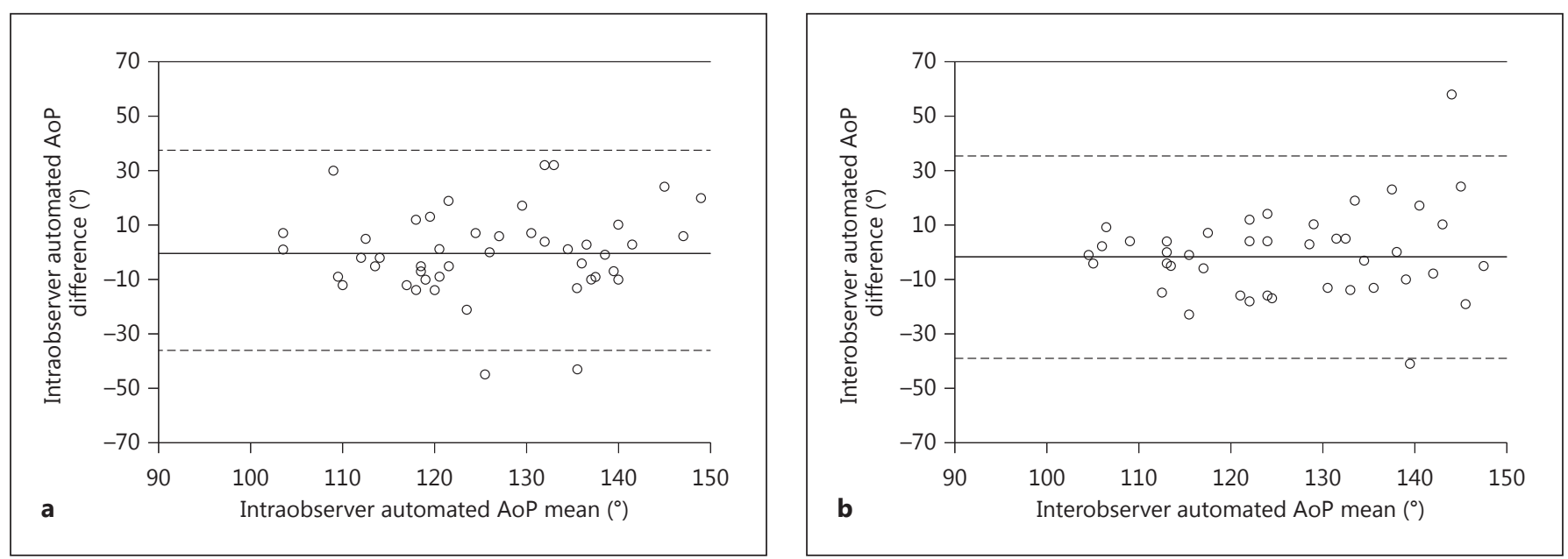

Fig. 4. Bland-Altman plots of intra- (a) and interobserver (b) agreement of the automated technique, in addition to the intermethod (c) agreement between the automated and manual techniques for the measurement of the AoP. Lines show the mean difference and $95 \%$ limits of the agreement (i.e. mean difference \pm $1.96 \mathrm{SD})$

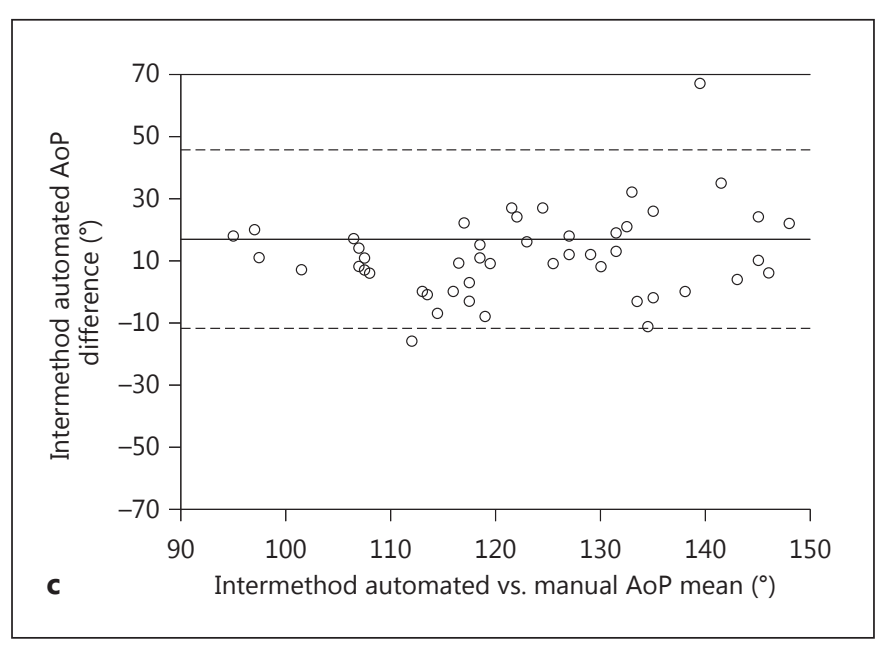

Automated Measurement of Angle of Progression 
Fig. 5. An illustration of one of the identified possible sources of the systematic difference between the automated and manual techniques explained on an illustrative design (a) and on a midsagittal transperineal ultrasound image (b). The automated software often depicts the echogenic center of the pubic symphysis (line $\mathrm{x}$ ), whereas the manual method includes the whole length of the pubic symphysis (line $\mathrm{x}+$ line $\mathrm{y}$ ). In that case, angle 1 formed by the automated technique will be invariably greater than angle 2 (manual technique).
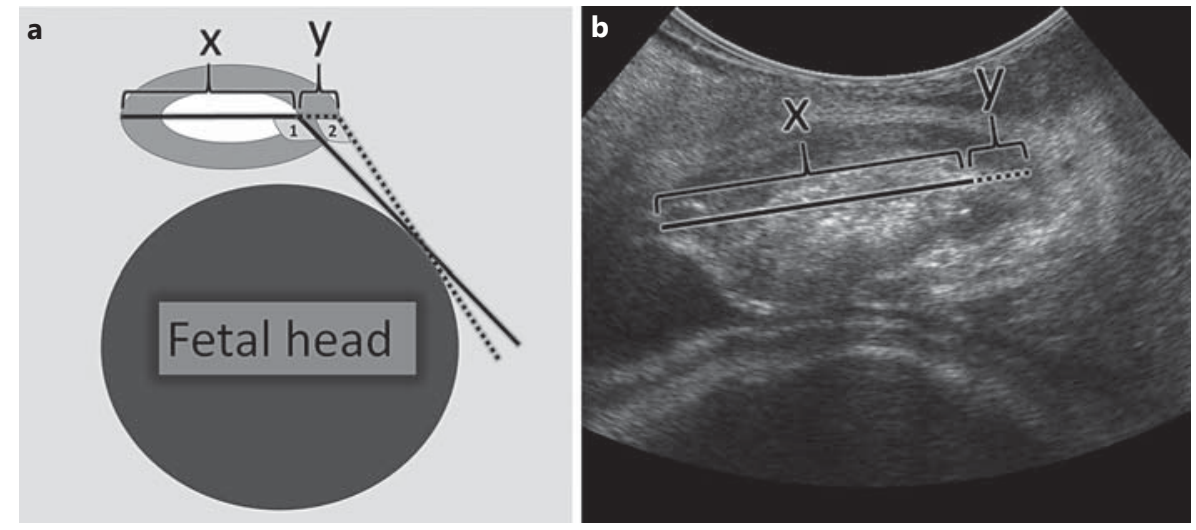

provides an accurate means for assessing descent of the fetal head during labor [4]. AoP measurement is highly reproducible regardless of the fetal head station or ultrasound expertise $[4,13,16]$. In addition, AoP width has a good correlation with labor outcome and may lead to better management in women with prolonged or obstructed labor $[6,7,17,19,30]$. Most importantly, since AoP is a strong predictor of complicated or failed instrumental delivery, its assessment may lead to better decision making before vacuum or forceps delivery $[6,18$, 31-33].

Very little is known, however, on the extent of use of ultrasound outside a research context. In a survey, which included more than 264 obstetricians, two thirds of the participants thought that the currently suggested ITU parameters are too complex to be applied in clinical practice [21]. The present study may play a very important role in overcoming that obstacle by automatically calculating the AoP once the operator obtains the midsagittal view.

We would like to highlight here that although we did not compare the time needed to assess the AoP using manual versus automated measurements, we do not think that the latter would offer a significant advantage regarding the speed of the assessment. Although automated measurements are much simpler to perform, once a learning curve for manual measurements is accomplished, we think that they are relatively quick to perform.

Although the new software is very promising and may prove to be instrumental in the promotion of a more widespread use of ITU in the labor ward, we think that its application in the time being is limited by the systematic overestimation of the AoP. Such overestimation may lead to a false impression of a low head station, which may end in an application of an instrumental delivery on fetuses

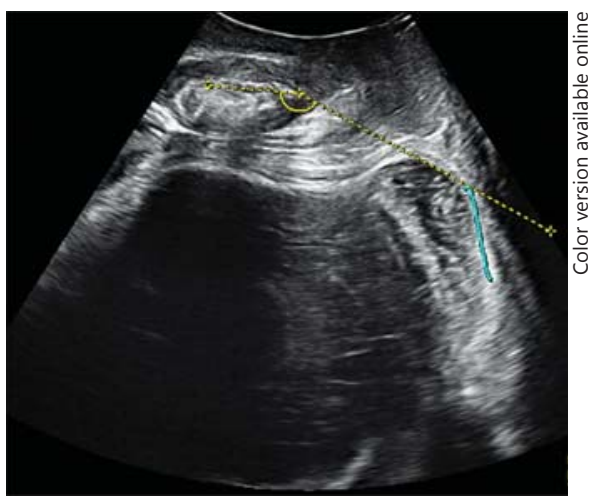

Fig. 6. An example of a case of automated AoP measurement in which the fetal skull line passes through a large fetal caput, significantly overestimating the AoP.

with a higher-than-expected head station, resulting in an increased perinatal risk. In the present study, we identified some potential causes of the significant difference between automatically and manually measured angles. This may be used in order to improve the accuracy and reliability of the software. A possible way to do so may be the use of a semi-automated technique, where the sonographer would mark the central axis of the pubic symphysis on the screen, thus reducing the odds of an erroneous measurement. Meanwhile, we believe that it should be used exclusively for research purposes.

To sum up, automated assessment of the AoP is feasible and reproducible. The automated software in its present form seems to overestimate systematically the AoP. Further improvement of the software accuracy and research are needed before recommending its use in clinical practice. 


\section{References}

1 Dietz HP, Lanzarone V: Measuring engagement of the fetal head: validity and reproducibility of a new ultrasound technique. Ultrasound Obstet Gynecol 2005;25:165-168.

2 Henrich W, Dudenhausen J, Fuchs I, Kamena A, Tutschek B: Intrapartum translabial ultrasound (ITU): sonographic landmarks and correlation with successful vacuum extraction. Ultrasound Obstet Gynecol 2006;28: 753-760.

3 Eggebo TM, Heien C, Okland I, Gjessing LK, Romundstad P, Salvesen KA: Ultrasound assessment of fetal head-perineum distance before induction of labor. Ultrasound Obstet Gynecol 2008;32:199-204

4 Barbera AF, Pombar X, Perugino G, Lezotte DC, Hobbins JC: A new method to assess fetal head descent in labor with transperineal ultrasound. Ultrasound Obstet Gynecol 2009; 33:313-319.

5 Ghi T, Farina A, Pedrazzi A, Rizzo N, Pelusi G, Pilu G: Diagnosis of station and rotation of the fetal head in the second stage of labor with intrapartum translabial ultrasound. Ultrasound Obstet Gynecol 2009;33:331-336.

6 Kalache KD, Duckelmann AM, Michaelis SA, Lange J, Cichon G, Dudenhausen JW: Transperineal ultrasound imaging in prolonged second stage of labor with occipitoanterior presenting fetuses: how well does the 'angle of progression' predict the mode of delivery? Ultrasound Obstet Gynecol 2009;33:326-330.

7 Torkildsen EA, Salvesen KA, Eggebo TM: Prediction of delivery mode with transperineal ultrasound in women with prolonged first stage of labor. Ultrasound Obstet Gynecol 2011;37:702-708

8 Tutschek B, Braun T, Chantraine F, Henrich W: A study of progress of labour using intrapartum translabial ultrasound, assessing head station, direction, and angle of descent. BJOG 2011;118:62-69.

9 Tutschek B, Braun T, Chantraine F, Henrich W: Quantification of fetal head direction and descent. Ultrasound Obstet Gynecol 2013;41: 99-100.

10 Youssef A, Maroni E, Ragusa A, De Musso F, Salsi G, Iammarino MT, Paccapelo A, Rizzo N, Pilu G, Ghi T: Fetal head-symphysis distance: a simple and reliable ultrasound index of fetal head station in labor. Ultrasound $\mathrm{Ob}$ stet Gynecol 2013;41:419-424.

11 Dupuis O, Silveira R, Zentner A, Dittmar A, Gaucherand P, Cucherat M, Redarce T, Rudigoz RC: Birth simulator: reliability of transvaginal assessment of fetal head station as defined by the American College of Obstetricians and Gynecologists classification. Am J Obstet Gynecol 2005;192:868-874.
12 Ghi T, Contro E, Farina A, Nobile M, Pilu G: Three-dimensional ultrasound in monitoring progression of labor: a reproducibility study. Ultrasound Obstet Gynecol 2010;36:500-506.

13 Molina FS, Terra R, Carrillo MP, Puertas A, Nicolaides KH: What is the most reliable ultrasound parameter for assessment of fetal head descent? Ultrasound Obstet Gynecol 2010;36:493-499.

14 Torkildsen EA, Salvesen KA, Eggebo TM: Agreement between two- and three-dimensional transperineal ultrasound methods in assessing fetal head descent in the first stage of labor. Ultrasound Obstet Gynecol 2012;39: 310-315.

15 Youssef A, Bellussi F, Montaguti E, Maroni E, Salsi G, Morselli-Labate AM, Paccapelo A, Rizzo N, Pilu G, Ghi T: Agreement between two- and three-dimensional transperineal ultrasound methods for assessment of fetal head-symphysis distance in active labor. Ultrasound Obstet Gynecol 2014;43:183-188.

16 Duckelmann AM, Bamberg C, Michaelis SA, Lange J, Nonnenmacher A, Dudenhausen JW, Kalache KD: Measurement of fetal head descent using the 'angle of progression' on transperineal ultrasound imaging is reliable regardless of fetal head station or ultrasound expertise. Ultrasound Obstet Gynecol 2010; 35:216-222.

17 Eggebo TM, Hassan WA, Salvesen KA, Lindtjorn E, Lees CC: Sonographic prediction of vaginal delivery in prolonged labor: a twocenter study. Ultrasound Obstet Gynecol 2014;43:195-201.

18 Cuerva MJ, Bamberg C, Tobias P, Gil MM, De La Calle M, Bartha JL: Use of intrapartum ultrasound in the prediction of complicated operative forceps delivery of fetuses in non-occiput posterior position. Ultrasound Obstet Gynecol 2014;43:687-692.

19 Ghi T, Youssef A, Maroni E, Arcangeli T, De Musso F, Bellussi F, Nanni M, Giorgetta F, Morselli-Labate AM, Iammarino MT, Paccapelo A, Cariello L, Rizzo N, Pilu G: Intrapartum transperineal ultrasound assessment of fetal head progression in active second stage of labor and mode of delivery. Ultrasound Obstet Gynecol 2013;41:430-435.

20 Youssef A, Maroni E, Cariello L, Bellussi F, Montaguti E, Salsi G, Morselli-Labate AM, Paccapelo A, Rizzo N, Pilu G, Ghi T: Fetal head-symphysis distance and mode of delivery in the second stage of labor. Acta Obstet Gynecol Scand 2014;93:1011-1017.

21 Youssef A, Ghi T, Awad EE, Maroni E, Montaguti E, Rizzo N, Pilu G: Ultrasound in labor: a caregiver's perspective. Ultrasound Obstet Gynecol 2013;41:469-470.
22 Youssef A, Bellussi F, Maroni E, Pilu G, Rizzo $\mathrm{N}$, Ghi T: Ultrasound in labor: is it time for a more simplified approach? Ultrasound $\mathrm{Ob}$ stet Gynecol 2013;41:710-711.

23 Espinoza J, Good S, Russell E, Lee W: Does the use of automated fetal biometry improve clinical work flow efficiency? J Ultrasound Med 2013;32:847-850.

24 American College of Obstetrics and Gynecology: Operative vaginal delivery. Clinical management guidelines for obstetrician-gynecologists. Int J Gynaecol Obstet 2001;74:69-76.

25 Rankin G, Stokes M: Reliability of assessment tools in rehabilitation: an illustration of appropriate statistical analyses. Clin Rehabil 1998;12:187-199.

26 Bland JM, Altman DG: Applying the right statistics: analyses of measurement studies. Ultrasound Obstet Gynecol 2003;22:85-93.

27 Bland JM, Altman DG: Measuring agreement in method comparison studies. Stat Methods Med Res 1999;8:135-160.

28 Tutschek B, Torkildsen EA, Eggebo TM: Comparison between ultrasound parameters and clinical examination to assess fetal head station in labor. Ultrasound Obstet Gynecol 2013;41:425-429.

29 Molina FS, Nicolaides KH: Ultrasound in labor and delivery. Fetal Diagn Ther 2010;27: 61-67.

30 Ghi T, Maroni E, Youssef A, Morselli-Labate AM, Paccapelo A, Montaguti E, Rizzo N, Pilu G: Sonographic pattern of fetal head descent: relationship with duration of active second stage of labor and occiput position at delivery. Ultrasound Obstet Gynecol 2014;44:82-89.

31 Bultez T, Quibel T, Bouhanna P, Popowski T, Resche-Rigon M, Rozenberg P: Angle of progression of the fetal head measured by transperineal ultrasound as a predictive factor of vacuum extraction failure. Ultrasound Obstet Gynecol 2016;48:86-91.

32 Sainz JA, Borrero C, Aquise A, Serrano R Gutierrez L, Fernandez-Palacin A: Utility of intrapartum transperineal ultrasound to predict cases of failure in vacuum extraction attempt and need of cesarean section to complete delivery. J Matern Fetal Neonatal Med 2016:29:1348-1352.

33 Sainz JA, Borrero C, Fernandez-Palacin A Aquise A, Valdivieso P, Pastor L, Garrido R: Intrapartum transperineal ultrasound as a predictor of instrumentation difficulty with vacuum-assisted delivery in primiparous women. J Matern Fetal Neonatal Med 2015; 28:2041-2047.
Automated Measurement of Angle of Progression
Fetal Diagn Ther 2017;41:293-299

DOI: $10.1159 / 000448947$ 